\title{
A model of quiescent tumour microregions for evaluating multicellular resistance to chemotherapeutic drugs
}

\author{
HR Mellor', DJP Ferguson ${ }^{2}$ and R Callaghan*,I \\ 'Oxford Drug Resistance Group, Nuffield Department of Clinical Laboratory Sciences, John Radcliffe Hospital, University of Oxford, Oxford OX3 9DU, \\ UK, ${ }^{2}$ Ultrastructural Morphology Group, Nuffield Department of Clinical Laboratory Sciences, John Radcliffe Hospital, University of Oxford, Oxford OX3 \\ 9DU, UK
}

The quiescent cell population of tumours poses a barrier to the success of many cancer therapies. Most chemotherapeutic drugs target proliferating cells, but the growth fraction of many tumours is low. Based on the multicellular tumour spheroid model, a system was developed using human colon adenocarcinoma (DLD-I) cells to mimic the microenvironment of quiescent microregions of solid tumours. The quiescent tumour spheroids $\left(\mathrm{TS}^{\mathrm{Q}}\right)$ showed decreased expression of the proliferation marker Ki-67 and increased expression of the quiescence marker $p 27^{k i p l}$ compared to proliferating spheroids $\left(T S^{P}\right)$. The quiescent status of the TS ${ }^{Q}$ was confirmed by long-term growth assessment. The quiescence was completely reversible demonstrating that the TS ${ }^{\mathrm{Q}}$ retained the ability to proliferate and morphological assessment by light microscopy confirmed the absence of significant apoptosis. When the efficacy of widely used chemotherapeutic drugs was determined, vinblastine, doxorubicin, cisplatin and 5-fluorouracil (5-FU) all produced significant cell death in the TS ${ }^{P}$. However, while still effective, the potencies of doxorubicin and cisplatin were significantly reduced in $\mathrm{TS}^{\mathrm{Q}}$. In contrast, 5-FU and vinblastine did not produce cell death in the $\mathrm{TS}^{\mathrm{Q}}$. In summary, $\mathrm{TS}^{\mathrm{Q}}$ show considerable resistance to a panel of established chemotherapeutic agents and represent a useful model for evaluating the efficacy of drugs and other cancer therapies in quiescent tumours.

British Journal of Cancer (2005) 93, 302-309. doi: I0.1038/sj.bjc.66027I0 www.bjcancer.com

Published online 19 July 2005

(c) 2005 Cancer Research UK

Keywords: quiescent; tumour; spheroid; microenvironment; chemotherapy; multicellular resistance

In many tumours, the actively dividing cells account for only a small proportion of the total, with the remainder of the cells being in a quiescent state (Q-cells) (Jackson, 1989). For particularly slow growing tumours (e.g. prostatic), a mean growth fraction of $<3 \%$ has been reported (Gallee et al, 1989; Berges et al, 1995). The quiescent cells within the tumour are viable but in a reversible state of growth arrest (Desoize and Jardillier, 2000). The mechanism behind the development of an intratumoural population of Q-cells remains unclear, but it may be a consequence of multiple microenvironmental factors, which result from the abnormal/inadequate vasculature often found within solid tumours (Brown and Giaccia, 1998). For example, hypoxia has been shown to evoke cell cycle arrest via the cyclin-dependent kinase (CDK) inhibitor p27 ${ }^{\text {kip1 }}$ (Gardner et al, 2001).

The relative expression levels of cellular proliferation (e.g. $\mathrm{Ki}-67$ ) and quiescence (e.g. p27 ${ }^{\mathrm{kip} 1}$ ) markers are valuable in determining the aggressiveness of tumours and therefore for predicting prognosis. A high proportion of Ki-67-positive cells in a tumour is indicative of a poor prognosis (Scholzen and Gerdes, 2000). Similarly, patients with tumours expressing low levels of p $27^{\text {kipl }}$ have a poorer prognosis than those whose tumours have

*Correspondence: Dr R Callaghan;

E-mail: richard.callaghan@ndcls.ox.ac.uk

Received 10 March 2005; accepted 17 June 2005; published online 19 July 2005 high $\mathrm{p} 27^{\mathrm{kip} 1}$ expression. Such correlations have been shown for many different human cancers (Blain et al, 2003). However, aggressive tumours with a high proportion of Ki-67-positive cells, despite imparting a poorer prognosis upon the patient, usually respond well to chemotherapy (Kamoi et al, 2001; Petit et al, 2004).

The selectivity of chemotherapeutic agents for killing proliferating cells (P-cells) over Q-cells has been demonstrated for many classes of drugs in cell monolayers (Valeriote and van Putten, 1975; Siu et al, 1999) and in the solid tumours of patients (Remvikos et al, 1993; Hietanen et al, 1995). In addition to their inherent chemoresistance, the inadequate vascularisation in tumour regions occupied by Q-cells leads to low local concentrations of drugs. As a consequence, the large Q-cell population of many human carcinomas (e.g. colon carcinoma, non-small-cell lung carcinoma) contributes to these tumours being refractory to many chemotherapy regimens (Jackson, 1989).

The insensitivity of Q-cells to chemotherapeutic drugs also contributes to the additional problem of regrowth resistance, through recruitment of the surviving Q-cells to the P-fraction after drug treatment (Brown and Giaccia, 1998; Siemann, 1998; Desoize and Jardillier, 2000). The low growth fraction of many tumours leads to the requirement for multiple repeated drug treatments over a prolonged time period (Shah and Schwartz, 2000). Finally, certain chemotherapeutic drugs can themselves induce quiescence in tumour cells (Carroll et al, 2003), rendering these cells refractory to the effects of further drug intervention. 
Therefore, an important question is how to treat those more indolent solid tumours that are chemoresistant due to a Q-cell population? Even for emerging cancer treatments such as gene therapy, tumour Q-cells pose a significant barrier to successful treatment. For example, the use of many retroviral vectors is significantly hampered by the dependence on host cell proliferation for viral replication (Patton et al, 2004). It is of paramount importance that we gain a greater insight into the efficacy of currently available therapies for killing tumour Q-cells and to develop novel drugs or therapeutic approaches that are more selective for this cell population.

In order to screen and evaluate chemotherapies and other therapeutic approaches, a suitable model system is required that is representative of the quiescent regions of solid tumours. Adapted monolayer cultures have been previously used to model populations of quiescent tumour cells (Phillips and Clayton, 1997; Horiatis et al, 2004). However, monolayers do not pose the barrier to drug penetration or provide many of the microenvironmental influences found in solid tumours and 3D cultures (Desoize and Jardillier, 2000). The multicellular tumour spheroid (MCTS) model (Inch et al, 1970; Sutherland et al, 1971; Hamilton, 1998) involves the culturing of cancer cell lines as 3D structures. In the absence of a suitable tissue culture system, we developed and evaluated a TS model of quiescent tumour microregions $\left(\mathrm{TS}^{\mathrm{Q}}\right)$ and compared them to proliferating spheroids $\left(\mathrm{TS}^{\mathrm{P}}\right)$. We chose to establish the TS using a DLD-1 human colon adenocarcinoma cell line as the mean doubling time of cancer of the colon is 90 weeks (Slingerland and Tannock, 1998) and this disease is synonymous with a poor chemotherapeutic response. To evaluate the usefulness of this new system, immunohistochemical detection of the proliferation marker Ki-67 and the quiescence marker p $27^{\mathrm{kip} 1}$ was performed to assess the localisation of P- and Q-cells within the TS. The longterm growth characteristics of both types of TS were measured and the viability of the $\mathrm{TS}^{\mathrm{Q}}$ after long-term quiescence was studied. In order to compare drug resistance profiles in the $\mathrm{TS}^{\mathrm{P}}$ and $\mathrm{TS}^{\mathrm{Q}}$, a novel method for quantifying cells within the spheroid mass was developed and utilised to test a series of commonly used chemotherapeutic agents. We chose to study the long-term response to drug treatment as discrepancies between short- and long-term responses have previously been observed when comparing the effects of drugs in P- and Q-cells (Siu et al, 1999).

\section{MATERIALS AND METHODS}

\section{Materials}

RPMI-1640 medium (with Glutamax I and 25 mM HEPES), foetal bovine serum (heat inactivated), penicillin/streptomycin solution and trypsin-EDTA were purchased from Life Technologies Ltd, UK. Methylene blue and fatty acid-free BSA were purchased from Sigma, UK. For the immunohistochemistry, Ki-67 and p27 kip1 mouse anti-human monoclonal antibodies were obtained from DakoCytomation, UK. Mach-2 polymer-HRP conjugate and peroxidazed 1 were from BioCarta, UK. Haematoxylin and aquamount were obtained from BDH Laboratory Supplies, UK. Vinblastine sulphate, doxorubicin hydrochloride and 5-fluorouracil (5-FU) were purchased from Sigma. Cisplatin was obtained from Professor Trevor W Hambley (University of Sydney, Australia).

\section{Cell lines, culture and TS production}

DLD-1 human colon adenocarcinoma cells were obtained from Dr Roger Phillips (University of Bradford, UK) and were grown as monolayers in RPMI-1640 medium (with Glutamax I and $25 \mathrm{~mm}$ HEPES) supplemented with $10 \%\left(\mathrm{v} \mathrm{v}^{-1}\right)$ fetal bovine serum and penicillin $\left(100 \mathrm{IU} \mathrm{ml}^{-1}\right) /$ streptomycin $\left(100 \mathrm{mg} \mathrm{ml}^{-1}\right)$. For most experiments, TS of DLD-1 cells were grown in spinner flasks (Techne, UK). A mother dish was prepared by coating the base of a T75 $\mathrm{cm}^{2}$ cell culture flask with $20 \mathrm{ml}$ of $0.75 \%\left(\mathrm{w} \mathrm{v}^{-1}\right)$ agarose prepared in medium without serum. Exponentially growing DLD-1 cells were added in $20 \mathrm{ml}$ of medium at a density of $1.5 \times 10^{6}$ cells $\mathrm{ml}^{-1}$ and the flask was left stationary for $24 \mathrm{~h}\left(37^{\circ} \mathrm{C}, 5 \% \mathrm{CO}_{2}\right)$. Any large-cell aggregates were removed by gravity sedimentation and the remaining small aggregates were transferred to a $500 \mathrm{ml}$ spinner culture flask and made to a total volume of $100 \mathrm{ml}$ of serum containing medium. The spinner flask was then placed on a stirrer (Techne MCS-1045) at $37^{\circ} \mathrm{C}, 5 \% \mathrm{CO}_{2}$ for an initial period of 3 days to allow the $\mathrm{TS}^{\mathrm{P}}$ to form. To generate $\mathrm{TS}^{\mathrm{Q}}$, the $\mathrm{TS}^{\mathrm{P}}$ were washed with PBS and fresh medium containing $0.1 \%$ fatty acid-free BSA instead of $10 \%$ FCS was added. For continuous culturing of $\mathrm{TS}^{\mathrm{P}}$ and $\mathrm{TS}^{\mathrm{Q}}$, the appropriate medium was refreshed $(50 \mathrm{ml})$ every other day.

\section{TS growth curves}

In order to monitor growth of $\mathrm{TS}^{\mathrm{Q}}$ and $\mathrm{TS}^{\mathrm{P}}$, TS were removed from the spinner flask to a Petri dish in a small volume of medium. The diameter of TS $(n \simeq 20)$ was measured daily, at the same time of day, and after measurements had been taken, the TS were replaced in the spinner flask. A graduated calibrated microscope eyepiece graticule (Pyser-SGI, UK) was used to measure TS diameter. TS diameter was converted into micrometers $(\mu \mathrm{m})$, which allowed calculation of TS volume $\left(\mu \mathrm{m}^{3}\right)$. Growth curves for TS represent the mean \pm s.e.m. of three independent experiments.

\section{Routine histological procedures}

TS were harvested, washed in PBS and fixed in neutral-buffered formalin ( $\mathrm{pH} 7.0)$. The TS were transferred to small plastic casting moulds for embedding, allowed to settle and the formalin removed. The moulds were filled with melted $2 \%\left(\mathrm{wv}^{-1}\right)$ agarose in $4 \%\left(\mathrm{v} \mathrm{v}^{-1}\right)$ formaldehyde. The agarose was allowed to set on ice before being removed from the mould and placed in a tissue cassette, which was routinely processed (Histopathology Department, John Radcliffe Hospital, Oxford, UK). The processed, agarose-embedded, TS were embedded in paraffin wax and $5 \mu \mathrm{m}$ sections were cut.

\section{Proliferation status of $\mathrm{TS}^{\mathrm{P}}$ and $\mathrm{TS}^{\mathrm{Q}}$ : Ki-67 and $\mathrm{p} 27^{\text {kip1 }}$}

TS sections (day 12) were completely dewaxed and rehydrated with PBS, placed in $50 \mathrm{~mm}$ Tris/200 mM EDTA buffer, $\mathrm{pH} 9.0$, and antigen retrieval was carried out in a Decloaking Chamber Pro (Biocarta, UK) at $120^{\circ} \mathrm{C}$ for $30 \mathrm{~s}$. Sections were washed with PBS and incubated in a humidified chamber $\left(25^{\circ} \mathrm{C}\right)$ with peroxidazed for $10 \mathrm{~min}$ to inhibit endogenous peroxidase activity. After washing the sections with PBS, the primary monoclonal antibody (mouse anti-human), Ki-67 (1:100 in PBS) or p2 $7^{\text {kip } 1}$ (1:50 in PBS), was added for $45 \mathrm{~min}$ at RT. Mach-2 goat-anti-mouse HRP conjugate was added for $45 \mathrm{~min}$ and detection was achieved using DAB substrate chromagen. Sections were counterstained with haematoxylin and mounted with aquamount.

\section{Calibration of cell number in TS by methylene blue staining}

Freshly trypsinised DLD-1 cells taken from exponentially growing cultures were overlaid on solid agarose base-coats at densities ranging from $1 \times 10^{3}$ to $3 \times 10^{4}$ cells in $100 \mu \mathrm{l}$ medium. The cells were kept stationary for $24 \mathrm{~h}\left(37^{\circ}, 5 \% \mathrm{CO}_{2}\right)$ after which the plates were transferred to a Titramax 100 (Heidolph Instruments, Germany) and shaken at 300 r.p.m. for a further $24 \mathrm{~h}\left(37^{\circ} \mathrm{C}, 5 \%\right.$ $\mathrm{CO}_{2}$ ) to allow TS to form. The TS were moved to a new 'uncoated' well in a 48 -well plate, $500 \mu \mathrm{l}$ of fresh medium was added and TS 
were allowed to adhere for $48 \mathrm{~h}\left(37^{\circ} \mathrm{C}, 5 \% \mathrm{CO}_{2}\right)$. After this time, the medium was aspirated and replaced with $200 \mu \mathrm{l}$ of $5 \mathrm{gl}^{-1}$ methylene blue in methanol, for $30 \mathrm{~min}$, to fix and stain the cells. The wells were washed five times with tap water to remove excess dye and the plates were allowed to dry overnight $\left(25^{\circ} \mathrm{C}\right)$. The stained TS $^{\mathrm{P}}$ were solubilised with $200 \mu \mathrm{l}$ of $2 \%$ SDS by shaking on a Titramax 100 at 300 r.p.m. for $24 \mathrm{~h}\left(25^{\circ} \mathrm{C}\right)$. A $100 \mu$ l aliquot was taken from each well and placed in the well of a 96-well plate and the absorbance was measured at $650 \mathrm{~nm}$ in a Spectra Max 250 microplate reader (Molecular Devices, UK).

\section{Drug cytotoxicity measurements in TS}

Proliferating tumour spheroids were grown as described above and on day 6 (when they have no inherent Q-cells) were transferred in $100 \mu \mathrm{l}$ of fresh medium to 96 -well tissue culture plates, which had previously been given a $100 \mu \mathrm{l}$ base-coat of $0.75 \%\left(\mathrm{wv}^{-1}\right)$ agarose (prepared in RPMI-1640 medium). Drugs were prepared in medium at twice the desired concentration to give a final concentration range of $1 \mathrm{~nm}$ to $316 \mu \mathrm{M}$ (up to $1 \mathrm{~mm}$ for 5-FU) and $100 \mu \mathrm{l}$ aliquots were added to each well. After the $16 \mathrm{~h}$ incubation, the $\mathrm{TS}^{\mathrm{P}}$ were moved to a new 'uncoated' well in a 48 -well plate and $500 \mu \mathrm{l}$ of fresh medium added. The $\mathrm{TS}^{\mathrm{P}}$ were incubated for a further 6-day recovery period. After this time, the methylene blue assay was performed as described above.

The $\mathrm{TS}^{\mathrm{Q}}$ were generated from $\mathrm{TS}^{\mathrm{P}}$ at 6 days growth by switching the medium to serum-free as described above and all subsequent culturing of $\mathrm{TS}^{\mathrm{Q}}$ was performed in this medium. The drug exposure and recovery protocol used for $\mathrm{TS}^{\mathrm{P}}$ was applied to the $\mathrm{TS}^{\mathrm{Q}}$; however, a slightly modified staining procedure was applied due to nonadherent nature of the $\mathrm{TS}^{\mathrm{Q}}$. After the 6-day recovery period, $\mathrm{TS}^{\mathrm{Q}}$ were transferred to the wells of a round-bottomed 96-well plate, the medium was aspirated and $200 \mu \mathrm{l}$ of $5 \mathrm{gl}^{-1}$ methylene blue in methanol was added to each well for $30 \mathrm{~min}$. The dye was aspirated, and the fixed spheroids were washed three times with $250 \mu \mathrm{l}$ of tap water. The solubilisation procedure and absorbance measurements were performed as above.

\section{Morphological evaluation of TS}

For morphological examination and comparison of the different TS models, TS ${ }^{Q}$ at the end of the growth study (i.e. day 25) and $\mathrm{TS}^{\mathrm{P}}$ of equivalent size (approximately day 8) were used. For drug-treated samples, day $6 \mathrm{TS}^{\mathrm{P}}$ or $\mathrm{TS}^{\mathrm{Q}}$ were transferred to agarose-coated 96-well plates and exposed to vinblastine $(3 \mu \mathrm{M})$, doxorubicin $(3 \mu \mathrm{M})$ or cisplatin $(30 \mu \mathrm{M})$ for $48 \mathrm{~h}$. This period of exposure to the above concentrations of these drugs had previously been shown to result in morphologically observable cytotoxicity in proliferating TS (Hall et al, 2004). TS were washed in PBS and fixed in $4 \%$ glutaraldehyde in $0.1 \mathrm{~m}$ phosphate buffer. Samples were postfixed in osmium tetroxide, dehydrated in ethanol, treated with propylene oxide and embedded in Spurr's epoxy resin. Sections were cut at $1 \mu \mathrm{m}$ thick and were stained with Azure A. Morphological features were identified by light microscopy. The number of apoptotic and mitotic cells per spheroid section was counted.

\section{Data analysis}

Data analysis was performed using GraphPad Prism ${ }^{\mathrm{TM}}$ software. Spheroid growth data were fitted with an exponential growth curve using the equation $Y=A \mathrm{e}^{K X}$, where $Y$ is the spheroid volume $\left(\mu \mathrm{m}^{3}\right)$ and $X$ is time (days). $Y$ starts at $A$ and increases geometrically with a doubling time equal to $0.6932 / K$. The doubling times obtained from the curves were compared based on $95 \%$ confidence intervals using one-way ANOVA and Tukey's post-test. Drug cytotoxicity in TS was quantified using nonlinear regression as described in (Hall et al, 2004).

\section{RESULTS}

\section{TS markers of proliferation and quiescence}

Serum withdrawal is a well-established method of inducing quiescence in cultured cell lines and has previously been used to induce quiescence in DLD-1 cells (Shida et al, 2003). However, as far as we are aware, this approach has not previously been applied to TS. To characterise the proliferative changes occurring within the TS tissue, spheroids were immunostained for the proliferation marker Ki-67 and the quiescence marker p $27^{\text {kip } 1 .}$

Initial investigations examined the effect of serum withdrawal on Ki-67 expression in the TS. Prior to serum withdrawal $(t=0 \mathrm{~h})$, a large proportion of the cells within the tissue were Ki-67-positive, particularly those at the periphery, with a small nonproliferating population located at the centre of the TS (Figure 1), an expected feature of TS of intermediate size (day 12). After $24 \mathrm{~h}$ in serum-free medium, Ki-67 expression was relatively unchanged; however, by $48 \mathrm{~h}$ a dramatic decrease was evident. Moreover, the location of the few Ki-67-positive cells was no longer biased to the periphery. A further decrease in expression was seen after $72 \mathrm{~h}$, by which point only a residual number of cells appeared to be proliferating (Figure 1).

In addition to the dramatic decrease observed in the number of Ki-67-positive cells within the TS, a concurrent increase in p27 $7^{\text {kip } 1}$ positive cells was seen during the $72 \mathrm{~h}$ period of serum starvation. Initially $(t=0 \mathrm{~h})$, the central region of the TS contained a number of p $27^{\mathrm{kip} 1}$-positive cells (Figure 1), consistent with the absence of $\mathrm{Ki}-67$ staining in this region. However, in contrast to the dramatic decrease in KI-67 that occurred between 24 and $48 \mathrm{~h}, \mathrm{p} 27^{\text {kip } 1}$ expression increased gradually over the $72 \mathrm{~h}$ period. At $72 \mathrm{~h}$, almost every cell was found to be p $27^{\text {kip } 1}$-positive, consistent with the almost complete absence of $\mathrm{Ki}-67$ expression at this time (Figure 1). The change in Ki-67/p2 $7^{\mathrm{kip} 1}$ expression was reversible, over a $72 \mathrm{~h}$ period, upon readministration of serum-containing medium (data not shown).

\section{Growth curves of $\mathrm{TS}^{\mathrm{Q}}$ and $\mathrm{TS}^{\mathrm{P}}$}

The growth rates of the quiescent spheroids $\left(\mathrm{TS}^{\mathrm{Q}}\right)$ were compared with those of actively proliferating spheroids $\left(\mathrm{TS}^{\mathrm{P}}\right)$ to further characterise the model. As shown in Figure 2, the effect of culturing TS in serum-free medium was dramatic. From day 3 , when the medium was changed, the curves for the $\mathrm{TS}^{\mathrm{P}}$ and $\mathrm{TS}^{\mathrm{Q}}$ diverged. The $\mathrm{TS}^{\mathrm{P}}$ displayed sustained, exponential growth, which continued up to day 17 when the spheroid volume was $\sim 0.28 \mu \mathrm{m}^{3}$ $(d \simeq 800 \mu \mathrm{m})$. At this point, the spheroids collapsed, most likely due to the large area of central necrosis that the $\mathrm{TS}^{\mathrm{P}}$ developed by this late stage. In comparison, the $\mathrm{TS}^{\mathrm{Q}}$ showed minimal growth on a day-to-day basis, although an increase in spheroidal volume $\left(0.007 \pm 0.002\right.$ to $\left.0.036 \pm 0.008 \mu \mathrm{m}^{3}\right)$ was evident over the 25 -day observation period (Figure 2). This small volume increase indicates that a small proportion of cells were capable of proliferation even in the absence of serum. The growth differences between the two types of TS is highlighted by the fact that between day 3 and day 17 , the $\mathrm{TS}^{\mathrm{P}}$ demonstrated a 48 -fold increase in volume compared to only a 2.5 -fold increase for the $\mathrm{TS}^{\mathrm{Q}}$.

The aim of developing the $\mathrm{TS}^{\mathrm{Q}}$ model was to enable examination of the sensitivity of quiescent tumour microregions to chemotherapeutic agents. In order to achieve this, it was important to establish that the serum-free medium used to generate the model did not have any deleterious effects on the viability of cells within the $\mathrm{TS}^{\mathrm{Q}}$, other than to restrict cell division. Therefore, the reversibility of the serum withdrawal was checked by replacing the $\mathrm{TS}^{\mathrm{Q}}$ growth medium with serum-replete. This was carried out on day 10 and again on day 15 and the ability of the $\mathrm{TS}^{\mathrm{Q}}$ to proliferate was assessed. The addition of serum to the culture medium rapidly returned the $\mathrm{TS}^{\mathrm{Q}}$ to a proliferative state (Figure 2). 

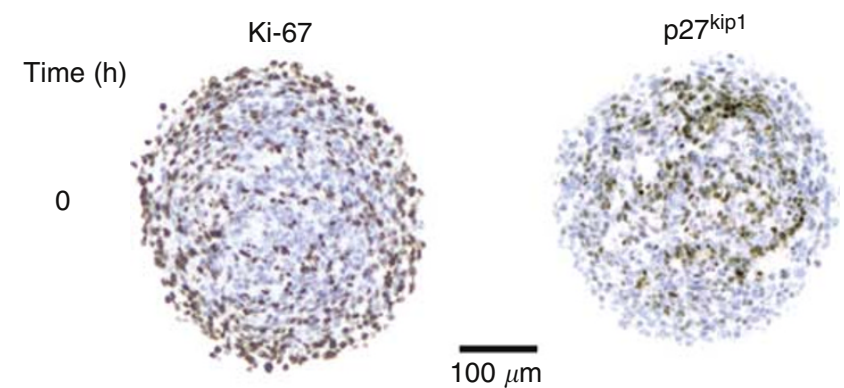

24
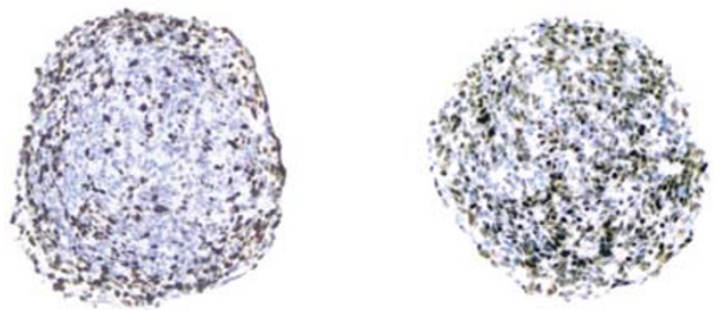

48

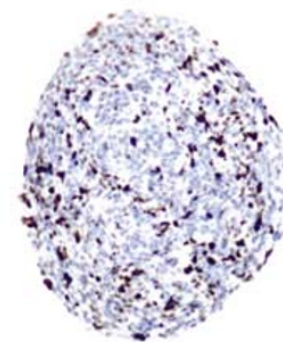

72

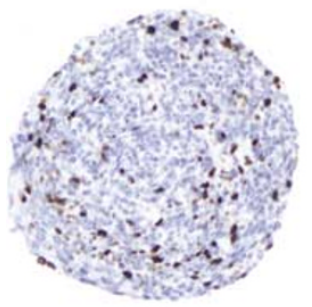

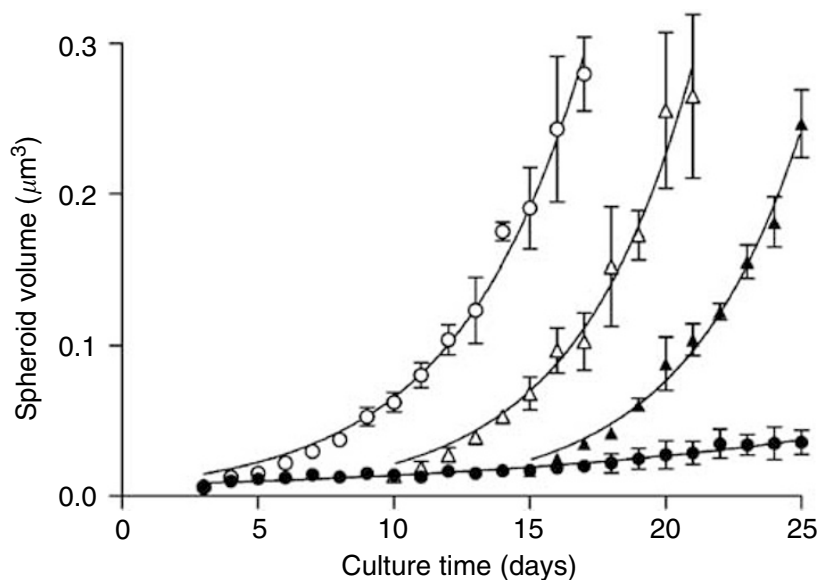

Figure 2 Growth curves for TS and reversibility of long-term quiescence. To generate $\mathrm{TS}^{\mathrm{Q}}$ (black circles), 3 days after seeding the spinner flask (day 3) $T^{P}$ (open circles) were washed with PBS and fresh medium was added containing $0.1 \%$ fatty acid-free BSA instead of $10 \%$ FCS. To assess the reversibility of the growth arrest evoked by serum withdrawal, the $\mathrm{TS}^{\mathrm{Q}}$ growth medium was switched back to serumcontaining day 10 (open triangles) and again on day I5 (closed triangles). For continuous culturing of $\mathrm{TS}^{\mathrm{P}}$ and $\mathrm{TS}^{\mathrm{Q}}$, the appropriate medium was refreshed $(50 \mathrm{ml})$ every other day. In order to monitor growth of TS ${ }^{\mathrm{Q}}$ and $T_{S} P$, TS were removed from the spinner flask to a Petri dish in a small volume of medium. The diameter of TS $(n \simeq 20)$ was measured daily and was used to calculate TS volume $\left(\mu \mathrm{m}^{3}\right)$. Growth curves represent the mean \pm s.e.m. of three independent experiments.

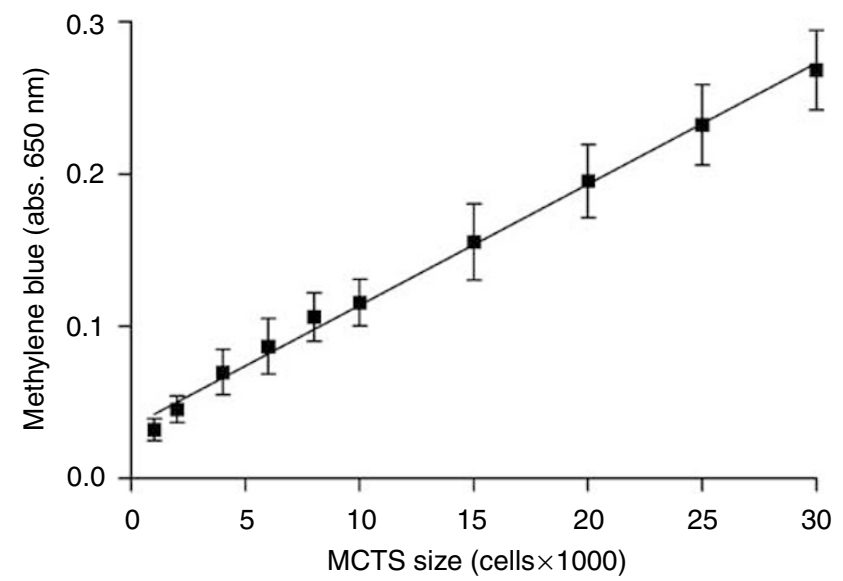

Figure 3 Standard curve for methylene blue staining against TS cell number. To ensure methylene blue staining was representative of the total number of cells present in a 3D TS, the assay was performed on TS of defined cell number from $1 \times 10^{3}$ to $3 \times 10^{4}$ cells. Staining, solubilisation and absorbance measurements were carried out and the standard curve of absorbance against TS cell number was plotted.

blue TS outgrowth assay. The original assay was unsuitable for the nonproliferating $\mathrm{TS}^{\mathrm{Q}}$ due to the lack of cellular outgrowth. Consequently, the assay was modified to quantify the amount of dye associated with the TS after staining. This provided a reliable, quantitative measure of total TS cell number. The linearity of the assay was checked by generating TS with a wide range of sizes $\left(1 \times 10^{3}\right.$ to $3 \times 10^{4}$ cells $)$. A linear relationship was found between cell number and methylene blue absorbance for TS over the range of sizes tested (Figure 3), and therefore the assay was a way of assessing drug cytotoxicity in the TS.

TS of $\sim 1 \times 10^{4}$ cells (day 6 of spinner flask culture) were chosen for the cytotoxicity assays as these TS consisted entirely of proliferating cells and were within the linear range of sizes defined
To assess the cytotoxicity of various chemotherapeutic agents in $\mathrm{TS}^{\mathrm{Q}}$ and $\mathrm{TS}^{\mathrm{P}}$, we developed a modified version of the methylene 
by the standard curve (Figure 3 ). This allowed for substantial drug-induced cell loss to be measured. A $16 \mathrm{~h}$ drug exposure time was employed for the cytotoxicity assays, followed by a 6-day 'recovery' period designed to allow any cytotoxic effects imparted by the drugs to be fully realised in the $\mathrm{TS}^{\mathrm{P}}$ and $\mathrm{TS}^{\mathrm{Q}}$.

The drugs chosen were selected on the basis of their different mechanisms of action and due to their established and widespread use in the clinic. For all of the chemotherapeutic agents tested, the potency in the $\mathrm{TS}^{\mathrm{Q}}$ was significantly lower than that observed in the $\mathrm{TS}^{\mathrm{P}}$ (Table 1). All of the drugs demonstrated considerable cytotoxicity in the $\mathrm{TS}^{\mathrm{P}}$, vinblastine and doxorubicin being equipotent with an $\mathrm{IC}_{50}$ of $\sim 1 \mu \mathrm{M}$. Cisplatin $\left(\mathrm{IC}_{50} 3.3 \pm 1.2 \mu \mathrm{M}\right)$ and 5-FU ( $\mathrm{IC}_{50} 25 \pm 8 \mu \mathrm{M}$ ) also produced significant inhibition of $\mathrm{TS}^{\mathrm{P}}$ growth, although their potencies were reduced. The extent of cell kill at the maximum drug concentration was high for all of the drugs ( $>85 \%$ see Table 1), demonstrating that the majority of cells within the $\mathrm{TS}^{\mathrm{P}}$ were drug-sensitive. Despite the high concentrations of drugs used (up to $316 \mu \mathrm{M}$ except 5-FU (1 mM)), the TS were mostly insensitive to the effects of two of the agents, the vinca alkaloid vinblastine and the antimetabolite 5-FU. The mean extent of cell kill was $34 \pm 12$ and $11 \pm 11 \%$ for the respective compounds. As a result of the lack of cytotoxicity, no meaningful $\mathrm{IC}_{50}$ was achievable for these compounds (Table 1).

In contrast, both doxorubicin and cisplatin displayed considerable cytotoxicity in the $\mathrm{TS}^{\mathrm{Q}}$. The potency of doxorubicin in the $\mathrm{TS}^{\mathrm{Q}}$ $(13 \pm 5 \mu \mathrm{M})$ was 16 -fold lower than that displayed in the $\mathrm{TS}^{\mathrm{P}}$ and the potency of cisplatin in the $\mathrm{TS}^{\mathrm{Q}}(84 \pm 30 \mu \mathrm{M})$ was 38 -fold lower than that displayed in the $\mathrm{TS}^{\mathrm{P}}$. As observed in the $\mathrm{TS}^{\mathrm{P}}$, the majority of the $\mathrm{TS}^{\mathrm{Q}}$ cells were sensitive to the effects of doxorubicin and cisplatin with a maximum cell kill of $81 \pm 10$ and $80 \pm 12 \%$, respectively.

\section{Morphological analysis of TS}

Morphological findings in the $\mathrm{TS}^{\mathrm{P}}$ and $\mathrm{TS}^{\mathrm{Q}}$ supported the previous experimental observations. A number of mitotic cells (mean 5.9 per TS, Figure 4E) were observed in the outer regions of the TS ${ }^{\mathrm{P}}$ (Figure $4 \mathrm{~A}$ ), but few (mean 0.33 per TS, Figure $4 \mathrm{E}$ ) were observed in the $\mathrm{TS}^{\mathrm{Q}}$ (Figure $4 \mathrm{~B}$ ). This is consistent with the change in expression of proliferation markers (Figure 1) and the difference in growth of the $\mathrm{TS}^{\mathrm{Q}}$ compared with the $\mathrm{TS}^{\mathrm{P}}$ (Figure 2). Long-term culturing of $\mathrm{TS}^{\mathrm{Q}}$ in $0.1 \%$ BSA (day 25) did not lead to an increase in the number of apoptotic bodies (Figure 4B) (mean 0.33 per TS section, Figure $4 \mathrm{E}$ ) compared to the $\mathrm{TS}^{\mathrm{P}}$ (mean 0.71 per TS section, Figure $4 \mathrm{E}$ ). This is consistent with growth arrest due to a decrease in mitosis and is not associated with increased apoptosis. It is also consistent with the finding that the quiescent status of the $\mathrm{TS}^{\mathrm{Q}}$ is fully reversible to $\mathrm{TS}^{\mathrm{P}}$ with no decrease in the rate of growth (Figure 2). There appeared to be some deposition of glycogen in the $\mathrm{TS}^{\mathrm{Q}}$, previously shown to be associated with decreased cell division rates in human colon carcinoma cell lines (Rousset et al, 1980), and therefore consistent with long-term culturing of DLD-1 TS ${ }^{\mathrm{Q}}$. Cisplatin-treated $\mathrm{TS}^{\mathrm{P}}$ contained a number of apoptotic bodies (Figure 4C). Although there were some apoptotic bodies in the cisplatin-treated $\mathrm{TS}^{\mathrm{Q}}$ (Figure $4 \mathrm{~F}$ ), there were often none in a particular field (Figure 4D). For all of the chemotherapeutic drugs, a reduced level of apoptosis was observed in the $\mathrm{TS}^{\mathrm{Q}}$ compared to the $\mathrm{TS}^{\mathrm{P}}$ (Figure $4 \mathrm{~F}$ ). This is consistent with the cytotoxicity assays where a decrease in the potencies of all of the drugs tested was observed in the $\mathrm{TS}^{\mathrm{Q}}$ relative to the $\mathrm{TS}^{\mathrm{P}}$ (Table 1).

\section{DISCUSSION}

In general, slowly growing tumours tend to be less drug-sensitive than rapidly growing tumours. Of the various cytokinetic factors that contribute to tumours having slow growth rates (e.g. long cycle times, high cell loss, Q-cells) (Riedel, 2002), modelling studies suggest that the presence of a large Q-cell compartment has the most serious implications for chemotherapy (Jackson, 1989). Most proliferation models are based on cell monolayers (Horiatis et al, 2004), but it is well established that for many chemotherapeutic drugs, a solid tissue environment affords an increased level of drug resistance (Desoize and Jardillier, 2000; Hall et al, 2004) called multicellular resistance. It is therefore of paramount importance in the evaluation of current and future therapies that a suitable system is developed to better represent the multicellular quiescent microregions in solid tumours.

Serum withdrawal is an established way of evoking growth arrest in proliferating cells, and although this approach has been used for DLD-1 cells (Shida et al, 2003), it has not previously been applied to TS. Ki-67 is a nuclear protein present during all active phases of the cell cycle in both normal and cancerous cells. It is expressed in $\mathrm{P}$-cells but not Q-cells and is therefore a useful marker for cellular proliferation (Endl and Gerdes, 2000; Scholzen and Gerdes, 2000). We observed that after $72 \mathrm{~h}$ in serum-free medium, very few cells within the TS expressed the protein and were therefore no longer proliferating. To observe the switch from proliferating to quiescent cells within the TS, immunostaining for $\mathrm{p} 27^{\mathrm{kip} 1}$ was performed. The levels of this protein are increased in quiescent cells (Lloyd et $a l, 1999)$ and constitutive expression in cultured cells leads to arrest in $G_{1}$ phase of the cell cycle (Toyoshima and Hunter, 1994). In response to serum withdrawal, we observed a dramatic increased in expression of $\mathrm{p} 27^{\mathrm{kip} 1}$ that was seen throughout the TS by $72 \mathrm{~h}$. This was consistent with the Ki-67 staining results and demonstrated that the cells had entered a quiescent state.

In addition to displaying markers of cellular quiescence, the $\mathrm{TS}^{\mathrm{Q}}$ showed minimal signs of growth over the 25-day measurement period. However, the spheroids retained the capacity for proliferation as was clear from the dramatic increase in TS size

Table I Efficacy of chemotherapeutic drugs in TS

\begin{tabular}{|c|c|c|c|c|}
\hline \multirow[b]{2}{*}{ Drug } & \multicolumn{2}{|r|}{$\mathbf{T S}^{\mathbf{P}}$} & \multicolumn{2}{|r|}{$\mathbf{T S}^{\mathbf{Q}}$} \\
\hline & $\mathrm{IC}_{50}(\mu \mathrm{M})$ & Extent of cell kill (\% of total cells) & $\mathrm{IC}_{50}(\mu \mathrm{M})$ & Extent of cell kill (\% of total cells) \\
\hline
\end{tabular}

$\mathrm{TS}^{\mathrm{P}}=$ proliferating tumour spheroids; $\mathrm{TS}^{\mathrm{Q}}=$ quiescent tumour spheroids; 5 -FU $=5$-fluorouracil. $\mathrm{TS}^{\mathrm{P}}$ and $\mathrm{TS}^{\mathrm{Q}}$ were exposed to a range of concentrations of chemotherapeutic drugs ( I nM to $316 \mu \mathrm{m}$ (up to I mM for 5-FU)) for $16 \mathrm{~h}$. The TS were incubated in drug-free medium for a further 6-day (recovery) period to allow the cytotoxic effects of the drugs to be realised. After this time, the methylene blue assay was performed. The potency of the drug to elicit cytotoxicity was expressed as an $\mathrm{IC}_{50}$ value determined from dose-response curves as described in the Materials and Methods. The extent of the cell kill in the TS was expressed as a percentage of control for the highest concentration of drug tested. Six replicates were performed for each drug concentration with the values obtained from three or more independent observations being shown as mean \pm s.e.m. andicates statistical significance $(P<0.05)$. 

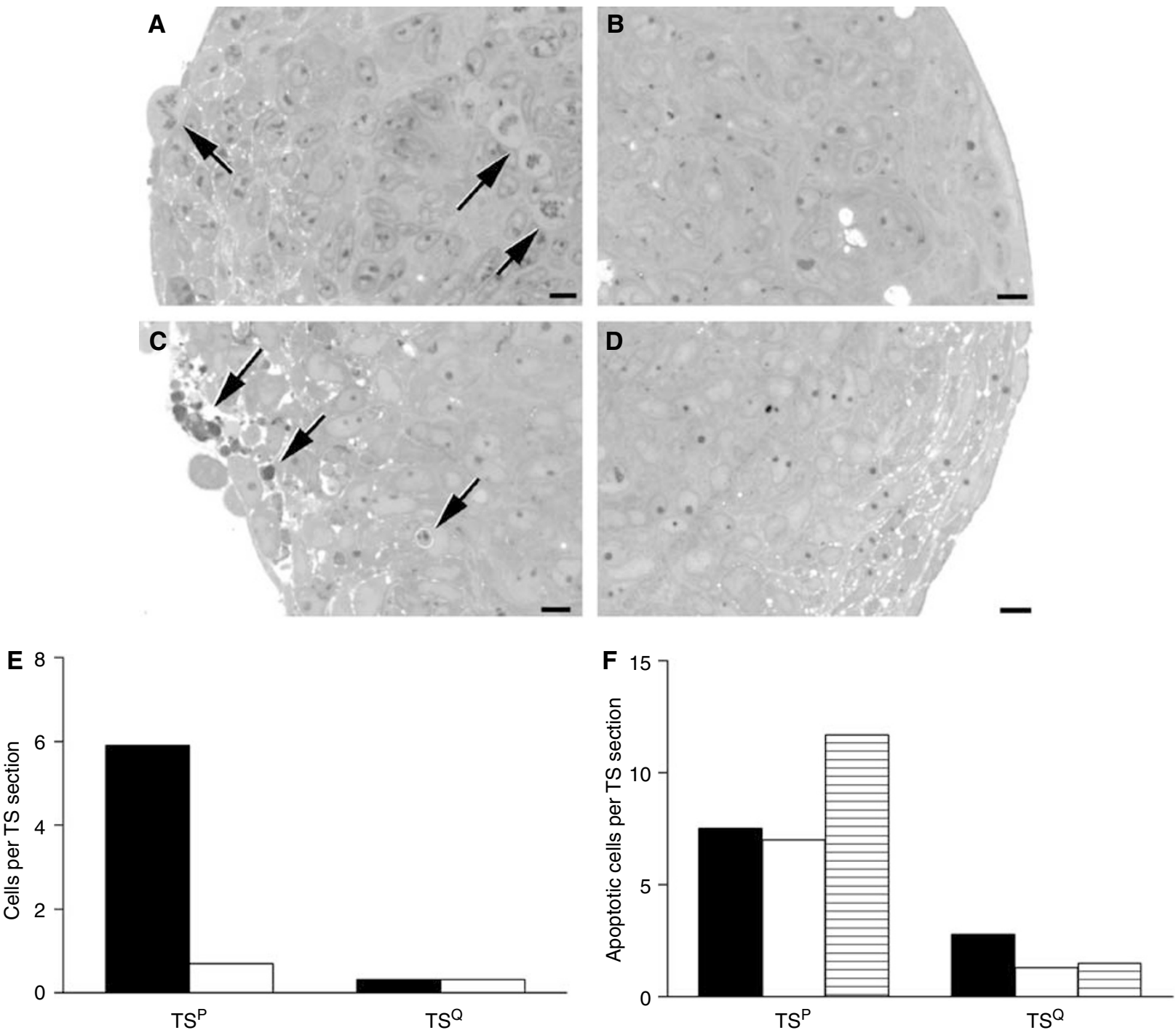

Figure 4 Effects of chemotherapeutic drug treatment on the morphology of TS. TS were fixed in $4 \%$ glutaraldehyde in 0.1 M phosphate buffer, postfixed in osmium tetroxide, dehydrated in ethanol, treated with propylene oxide and embedded in Spurr's epoxy resin. Sections were cut at I $\mu$ m thick and stained with Azure A. Images are representative of the typical appearance. The scale bar represents $10 \mu \mathrm{m}$. (A) Untreated TS showing a number of mitotic cells

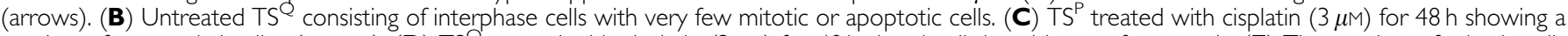
number of apoptotic bodies (arrows). (D) TS ${ }^{Q}$ treated with cisplatin $(3 \mu \mathrm{M})$ for $48 \mathrm{~h}$ showing little evidence of apoptosis. (E) The number of mitotic cells (black bars) and apoptotic bodies (white bars) expressed as a mean per spheroid section for TS $^{P}$ and TS $^{Q}$. (F) The number of apoptotic bodies in TS ${ }^{P}$ and TS $^{\mathrm{Q}}$ treated with doxorubicin (black bars), vinblastine (white bars) and cisplatin (lined bars) expressed as a mean per spheroid section.

when they were exposed to serum-containing medium. This proliferative potential retained by quiescent cells forms the basis for the regrowth resistance that arises after chemotherapy or ionising radiation treatments when these insensitive cells repopulate the tumour (Desoize and Jardillier, 2000). It was clear from both the proliferative response of the $\mathrm{TS}^{\mathrm{Q}}$ and the microscopy data that there were no deleterious effects of serum withdrawal on the $\mathrm{TS}^{\mathrm{Q}}$. This was an important factor in the use of the system for the assessment of drug-induced cytotoxicity.

In order to test our model, we exposed the $\mathrm{TS}^{\mathrm{Q}}$ and $\mathrm{TS}^{\mathrm{P}}$ to anticancer drugs with different mechanisms of action. All of the drugs were less effective in the $\mathrm{TS}^{\mathrm{Q}}$ relative to the $\mathrm{TS}^{\mathrm{P}}$, highlighting the inherent drug resistance of these quiescent microregions. The two phase-specific agents we studied, 5-FU (S phase) and vinblastine ( $M$ phase), were both ineffective in the multicellular environment of the $\mathrm{TS}^{\mathrm{Q}}$. The mechanism of action of the uracil analogue 5-FU is through incorporation of its metabolites into RNA and DNA and through thymidylate synthase inhibition
(Longley et al, 2003), which is required for DNA replication and repair. The inability of 5-FU to exert any cytotxicity in the $\mathrm{TS}^{\mathrm{Q}}$ is consistent with the lack of replicating cells compared to the $\mathrm{TS}^{\mathrm{P}}$. Vinblastine, along with vincristine, is a naturally occurring member of vinca alkaloid class of anticancer drugs. It is an antimitotic agent that blocks cells in metaphase through suppression of microtubule dynamics (Jordan and Wilson, 2004). The selectivity of the drug for cells undergoing mitosis explains why the nondividing $\mathrm{TS}^{\mathrm{Q}}$ were unresponsive to vinblastine administration.

The two phase-nonspecific agents, doxorubicin and cisplatin, while showing less efficacy in the $\mathrm{TS}^{\mathrm{Q}}$, maintained a significant cell kill. Cisplatin forms covalent adducts with DNA, the most prevalent being the 1, 2-intrastrand crosslink (Zamble and Lippard, 1995). The DNA adducts are detected by a range of damage recognition proteins, which leads to apoptosis or DNA repair and survival (Siddik, 2003). The relative sensitivities of P- and Q-cells to the initial DNA-platinum adduct formation 
remains unclear. However, replication is required for the formation of cisplatin-induced DNA double-strand breaks (Kaina, 2003). In addition, Q-cells in solid tumours in vivo have previously been shown to have greater DNA repair capacities than the total cell population in response to cisplatin (Masunaga et al, 1999). Cell cycle arrest is often considered inhibitory to the induction of cytotoxicity and is known to be important in enabling the nucleotide excision repair machinery to remove cisplatin adducts (Siddik, 2003). Therefore, the decreased sensitivity of the $\mathrm{TS}^{\mathrm{Q}}$ to cisplatin may be a result of the Q-cells having a greater capacity and/or more time to repair the cisplatin-induced DNA damage.

Doxorubicin displayed a decreased potency in the $\mathrm{TS}^{\mathrm{Q}}$ compared to the $\mathrm{TS}^{\mathrm{P}}$, indicating that the cytotoxic effects are only partly proliferation-dependent. A previous study also observed an increase in long-term survival and proliferation potential in doxorubicin-treated Q-cells over P-cells (Siu et al, 1999). The proliferation-independent cell death observed in the $\mathrm{TS}^{\mathrm{Q}}$ could result from one or more of the multiple activities of doxorubicin. These include free radical generation, lipid peroxidation, DNA adduct formation, interference with DNA unwinding and membrane-mediated effects (Gewirtz, 1999; Minotti et al, 2004).

To overcome the problem of these chemoresistant quiescent tumour cells, a greater understanding of the mechanisms regulating proliferation in cancer cells and how these operate in a multicellular tumour environment is required. One possible approach to restore chemotherapeutic sensitivity may be to inhibit temporarily the activity of $\mathrm{p} 27^{\mathrm{kip} 1}$ and therefore force the Q-cells into the cycle prior to drug administration. The validity of this approach has already been demonstrated in vitro by pretreating TS with antisense oligonucleotides to $\mathrm{p} 27^{\mathrm{kip} 1}$. This resulted in

\section{REFERENCES}

Berges RR, Vukanovic J, Epstein JI, CarMichel M, Cisek L, Johnson DE, Veltri RW, Walsh PC, Isaacs JT (1995) Implication of cell kinetic changes during the progression of human prostatic cancer. Clin Cancer Res 1: $473-480$

Blain SW, Scher HI, Cordon-Cardo C, Koff A (2003) p27 as a target for cancer therapeutics. Cancer Cell 3: 111-115

Brown JM, Giaccia AJ (1998) The unique physiology of solid tumors: opportunities (and problems) for cancer therapy. Cancer Res 58: $1408-1416$

Carroll JS, Lynch DK, Swarbrick A, Renoir JM, Sarcevic B, Daly RJ, Musgrove EA, Sutherland RL (2003) p27(Kip1) induces quiescence and growth factor insensitivity in tamoxifen-treated breast cancer cells. Cancer Res 63: $4322-4326$

Desoize B, Jardillier J (2000) Multicellular resistance: a paradigm for clinical resistance? Crit Rev Oncol Hematol 36: 193-207

Endl E, Gerdes J (2000) The Ki-67 protein: fascinating forms and an unknown function. Exp Cell Res 257: 231-237

Gallee MP, Visser-de Jong E, ten Kate FJ, Schroeder FH, Van der Kwast TH (1989) Monoclonal antibody Ki-67 defined growth fraction in benign prostatic hyperplasia and prostatic cancer. J Urol 142: $1342-1346$

Gardner LB, Li Q, Park MS, Flanagan WM, Semenza GL, Dang CV (2001) Hypoxia inhibits G1/S transition through regulation of p27 expression. J Biol Chem 276: 7919-7926

Gewirtz DA (1999) A critical evaluation of the mechanisms of action proposed for the antitumor effects of the anthracycline antibiotics adriamycin and daunorubicin. Biochem Pharmacol 57: 727-741

Hall MD, Martin C, Ferguson DJ, Phillips RM, Hambley TW, Callaghan R (2004) Comparative efficacy of novel platinum(IV) compounds with established chemotherapeutic drugs in solid tumour models. Biochem Pharmacol 67: $17-30$

Hamilton G (1998) Multicellular spheroids as an in vitro tumor model. Cancer Lett 131: 29-34

Hietanen P, Blomqvist C, Wasenius VM, Niskanen E, Franssila K, Nordling S (1995) Do DNA ploidy and S-phase fraction in primary tumour predict the response to chemotherapy in metastatic breast cancer? $\mathrm{Br} J$ Cancer 71: $1029-1032$ increased cellular proliferation and sensitised the tumour cells to 4-hydroperoxycyclophosphomide (St Croix et al, 1996). Any approach should ideally be selective for the killing of tumour Q-cells over the normal cells of the body, which are also mostly quiescent.

In summary, we have described a new derivative of the MCTS model that mimics quiescent microregions within solid tumours. Like those solid tumours in the clinic with low proliferative fractions, these $\mathrm{TS}^{\mathrm{Q}}$ show considerable resistance to a panel of established chemotherapeutic agents. The model described here would not only be useful for initial drug screening but also for assessing the long-term efficacy of drugs in quiescent tumour microregions. For example, after exposure to a chemotherapeutic drug, the $\mathrm{TS}^{\mathrm{Q}}$ could be maintained in a quiescent state for a defined period before being selectively returned to a proliferating state. This would mimic the recruitment of Q-cells to the proliferating fraction that occurs in solid tumours in vivo. Using this approach will enable examination of the longevity of drug damage in quiescent microregions and the factors influencing this such as DNA repair capacity. This model may also be useful in evaluating the penetration of viral/non-viral vectors in quiescent tumour tissue and the subsequent protein expression.

\section{ACKNOWLEDGEMENTS}

We thank Margaret Jones (LRF immunodiagnostics unit) for the kind use of the Decloaking Chamber Pro. The preparation of this manuscript was greatly assisted by the refreshing input of AL Toids. This research was funded by a Cancer Research UK Program grant (SP1861/0401). DJPF is supported by an equipment grant from the Wellcome Trust.
Horiatis D, Wang Q, Pinski J (2004) A new screening system for proliferation-independent anti-cancer agents. Cancer Lett 210: 119-124

Inch WR, McCredie JA, Sutherland RM (1970) Growth of nodular carcinomas in rodents compared with multi-cell spheroids in tissue culture. Growth 34: $271-282$

Jackson RC (1989) The problem of the quiescent cancer cell. Adv Enzyme Regul 29: $27-46$

Jordan MA, Wilson L (2004) Microtubules as a target for anticancer drugs. Nat Rev Cancer 4: 253-265

Kaina B (2003) DNA damage-triggered apoptosis: critical role of DNA repair, double-strand breaks, cell proliferation and signaling. Biochem Pharmacol 66: $1547-1554$

Kamoi S, Ohaki Y, Okada S, Matsushita N, Kawamura T, Araki T (2001) Mitotic index and ki-67 nuclear antigen labeling index as predictors of chemotherapy response in uterine cervical carcinoma. Gynecol Oncol 83: $555-559$

Lloyd RV, Erickson LA, Jin L, Kulig E, Qian X, Cheville JC, Scheithauer BW (1999) p27kipl: a multifunctional cyclin-dependent kinase inhibitor with prognostic significance in human cancers. Am J Pathol 154: $313-323$

Longley DB, Harkin DP, Johnston PG (2003) 5-Fluorouracil: mechanisms of action and clinical strategies. Nat Rev Cancer 3: 330-338

Masunaga S, Ono K, Hori H, Suzuki M, Kinashi Y, Takagaki M, Kasai S, Nagasawa H, Uto Y (1999) Potentially lethal damage repair by total and quiescent tumor cells following various DNA-damaging treatments. Radiat Med 17: 259-264

Minotti G, Menna P, Salvatorelli E, Cairo G, Gianni L (2004) Anthra cyclines: molecular advances and pharmacologic developments in antitumor activity and cardiotoxicity. Pharmacol Rev 56: 185-229

Patton GS, Erlwein O, McClure MO (2004) Cell-cycle dependence of foamy virus vectors. J Gen Virol 85: 2925-2930

Petit T, Wilt M, Velten M, Millon R, Rodier JF, Borel C, Mors R, Haegele P, Eber M, Ghnassia JP (2004) Comparative value of tumour grade, hormonal receptors, Ki-67, HER-2 and topoisomerase II alpha status as predictive markers in breast cancer patients treated with neoadjuvant anthracycline-based chemotherapy. Eur J Cancer 40: 205-211 
Phillips RM, Clayton MR (1997) Plateau-phase cultures: an experimental model for identifying drugs which are bioactivated within the microenvironment of solid tumours. $\mathrm{Br} J$ Cancer 75: $196-201$

Remvikos Y, Mosseri V, Zajdela A, Fourquet A, Durand JC, Pouillart P, Magdelenat H (1993) Prognostic value of the S-phase fraction of breast cancers treated by primary radiotherapy or neoadjuvant chemotherapy. Ann N Y Acad Sci 698: 193-203

Riedel H (2002) Models for tumour growth and differentiation. In The Cancer Handbook Vol. 2, D: Pre-Clinical Models for Human Cancer MA A (ed) pp 953-970. London: Nature Publishing Group

Rousset M, Dussaulx E, Chevalier G, Zweibaum A (1980) Growth-related glycogen levels of human intestine carcinoma cell lines grown in vitro and in vivo in nude mice. J Natl Cancer Inst 65: 885-889

Scholzen T, Gerdes J (2000) The Ki-67 protein: from the known and the unknown. J Cell Physiol 182: $311-322$

Shah MA, Schwartz GK (2000) The relevance of drug sequence in combination chemotherapy. Drug Resist Updat 3: 335-356

Shida D, Kitayama J, Yamaguchi H, Okaji Y, Tsuno NH, Watanabe T, Takuwa Y, Nagawa H (2003) Lysophosphatidic acid (LPA) enhances the metastatic potential of human colon carcinoma DLD-1 cells through LPA1. Cancer Res 63: $1706-1711$
Siddik ZH (2003) Cisplatin: mode of cytotoxic action and molecular basis of resistance. Oncogene 22: $7265-7279$

Siemann DW (1998) The tumor microenvironment: a double-edged sword. Int J Radiat Oncol Biol Phys 42: 697-699

Siu WY, Arooz T, Poon RY (1999) Differential responses of proliferating versus quiescent cells to adriamycin. Exp Cell Res 250: 131-141

Slingerland JM, Tannock IF (1998) Cell proliferation and cell death. In The Basic Science of Oncology Tannock IF, Hill RP (eds) pp 134-165. New York: McGraw-Hill

St Croix B, Florenes VA, Rak JW, Flanagan M, Bhattacharya N, Slingerland JM, Kerbel RS (1996) Impact of the cyclin-dependent kinase inhibitor p27Kip1 on resistance of tumor cells to anticancer agents. Nat Med 2: $1204-1210$

Sutherland RM, McCredie JA, Inch WR (1971) Growth of multicell spheroids in tissue culture as a model of nodular carcinomas. J Natl Cancer Inst 46: $113-120$

Toyoshima H, Hunter T (1994) p27, a novel inhibitor of G1 cyclin-Cdk protein kinase activity, is related to p21. Cell 78: $67-74$

Valeriote F, van Putten L (1975) Proliferation-dependent cytotoxicity of anticancer agents: a review. Cancer Res 35: 2619-2630

Zamble DB, Lippard SJ (1995) Cisplatin and DNA repair in cancer chemotherapy. Trends Biochem Sci 20: 435-439 